\title{
PENGARUH MODEL PEMBELAJARAN DISCOVERYLEARNINGTERHADAP HASIL BELAJAR SISWA PADA MATERI POKOK FLUIDA DINAMIS KELAS XI SEMESTER GENAP SMA NEGERI 1 BINJAI KABUPATEN LANGKAT T.P.2014/2015
}

\author{
Puteri Lestari dan Juniar Hutahaean \\ Jurusan Fisika FMIPA Universitas Negeri Medan \\ lestari.puteri@yahoo.com
}

\begin{abstract}
ABSTRAK
Penelitian ini bertujuan untuk mengetahui pengaruh model pembelajaran discovery learning terhadap hasil belajar siswa pada materi pokok Fluida Dinamis di kelas XI semester genap SMA Negeri 1 Binjai Kabupaten Langkat T.P 2014/2015. Jenis penelitian ini adalah quasi exsperiment. Populasi dalam penelitian adalah seluruh siswa kelas XI Semester Genap SMA Negeri 1 Binjai Kabupaten Langkat yang terdiri dari 3 kelas. Pengambilan sampel dilakukan dengan cara cluster random sampling,kelas XI IPA-1 sebagai kelas eksperimen dan kelas XI IPA-2 sebagai kelas kontrol. Kelas eksperimen berjumlah 40 orang dan kelas kontrol berjumlah 36 orang. Instrumen yang digunakan dalam penelitian ini ada 2, yaitupertama tes hasil belajar dalam bentuk pilihan berganda dengan jumlah 20 soalyang telah divalidkan oleh validator. Instrumen yang kedua adalah lembar observasi aktivitas belajar siswa untuk kelas eksperimen. Hasil pengujian pretessebelum diberikan perlakuan yang berbeda, yaitu nilai rata-rata pretes kelas eksperimen 32,62 dengan standar deviasi 8,39 dan nilai rata-rata pretes kelas kontrol 32,08 dengan standar deviasi 9,66. Selama proses pembelajaran, rata-rata aktivitas siswa dari pertemuan pertama sampai ketiga mengalami peningkatan sebesar $71,48,79,1$, dan 83,7. Setelah pembelajaran selesai, diperoleh postes dengan hasil rata-rata kelas eksperimen 73,87 dengan standar deviasi 9,96 dan kelas kontrol 61,11 dengan standar deviasi 10,15. Data pretes dan postes telah memenuhi prasyarat dan menyatakan ada perbedaan yang signifikankarena pengaruh model pembelajaran discovery learning terhadap hasil belajar siswa pada materi pokok Fluida Dinamis di kelas XI semester genap SMA Negeri 1 Binjai Kabupaten Langkat T.P 2014/2015.
\end{abstract}

Kata kunci : discovery learning, hasil belajar, fluida dinamis

\begin{abstract}
This research aims to knowing the influence of learning model Discovery learning on the results of student learning in the subject matter Fluid Dynamic in class XI second semester SMA Negeri 1 Binjai regencyLangkat period 2014/2015. This research is a quasi experimental. The population in the research were all students of class XI second semester SMA Negeri 1 Binjai regency Langkat consisting of 3 classes. Sampling was done by cluster random sampling, if class XI-IPA 1 as the experimental class and class XI-IPA 2 as the control class. Experimental class of 40 people and the control class of 36 people. The instrument used in this research there are two, the first test of results learning in the form of multiple-choice questions with 20 questions has been valid by the validator. The second instrument is the observation sheet student learning activity for the experimental class. The results of pretest before being given different treatment, which is the average value of the experimental class pretest 32.62 with a standard deviation of 8.39 and
\end{abstract}


average value pretest control class 32.08 with a standard deviation of 9.66. During the learning process, the average activity of the students at the first to three of increasing meeting of 71.48, 79.1, and 83.7. After the study obtained postes with an average results of 73.87 experimental class with a standard deviation of 9.96 and a control class 61.11 with a standard deviation of 10.15. Data pretest and posttest has met the prerequisites so there is a significant difference because influence of the learning model of discovery learning on student learning of students in the subject matter of Fluid Dynamic in class XI second semester SMANegeri 1 Binjai regency Langkat period 2014/2015.

Keywords: discovery learning, results of learning, fluid dynamic

\section{PENDAHULUAN}

Pendidikan merupakan segala situasi hidup yang mempengaruhi pertumbuhan individu sebagai pengalaman belajar yang berlangsung dalam segala lingkungan dan sepanjang hidup (Sagala, 2009).Tingkat pendidikan Indonesia berdasarkan kualitas pendidikan dunia di dapat dari Education For All (EFA) Global Monitoring Report yang dikeluarkan oleh UNESCO setiap tahunnya, pendidikan Indonesia berada diperingkat ke-64 untuk pendidikan diseluruh dunia dari 120 negara. Data Education Development Index (EDI) Indonesia, pada tahun 2011 Indonesia berada diperingkat ke-69 dari 127 negara.

Hal tersebut, sesuai dengan hasil observasi yang dilakukan oleh peneliti di SMA Negeri 1 Binjai Kabupaten Langkat, dengan memberikan daftar pertanyaan kepada 44 siswa, bahwa $45,71 \%$ siswa mengatakan fisika sulit dan kurang menarik, 31,57 \% siswa mengatakan fisika tidak terlalu sulit tapi kurang menarik dan $22,72 \%$ siswa mengatakan fisika menarik dan menyenangkan. Data di atas sejalan dengan kurang memuaskannya hasil belajar yang diperoleh siswa di kelas tersebut, hanya 10 siswa yang lulus Ujian Tengah Semester T.A. 2014/2015. Data tersebut diperoleh selama peneliti melakukan Program Pengalaman Lapangan Terpadu (PPLT) di SMA
Negeri 1 Binjai Kabupaten Langkat (Lestari, 2015).

Berdasarkan hasil wawancara pada guru fisika bahwa rendahnya hasil belajar fisika yang diperoleh siswa disebabkan karena guru selalu memakai pembelajaran konvensional yang dominan menggunakan metode ceramah dalam menyampaikan materi, meskipun kurikulum sudah berganti namun guru selalu memakai pola pengajaran yang sama yaitu guru sebagai pusat segalanya sehingga menimbulkan kejenuhan pada diri siswa. Selain itu juga disebabkan oleh kurang optimalnya penggunaan media selama proses pembelajaran serta faktor yang terdapat didalam diri siswa seperti sikap mereka terhadap pelajaran fisika, dimana mereka beranggapan bahwa pelajaran fisika lebih sulit karena penuh dengan rumus-rumus yang membingungkan, sehingga siswa tidak menyukai pelajaran fisika.

Peneliti menggunakan pembelajaran discovery learning, yaitu suatu model untuk mengembangkan cara belajar siswa aktif dengan menemukan sendiri, menyelidiki sendiri, maka hasil yang diperoleh akan setia dan tahan lama dalam ingatan, tidak akan mudah dilupakan siswa.(Hosnan, 2014). Selain itu menggunakan media animasi PhET untuk membuat siswa agar lebih tertarik dan tidak bosan saat belajar fisika. Media animasi PhET digunakan 
untuk memperjelas tentang materi pelajaran yang dipelajari.

Adapun tujuan dari pelaksanaan penelitian ini adalah: (1) Untuk mengetahui hasil belajar siswa dengan menggunakan model pembelajaran Discovery learning pada materi pokok Fluida Dinamis di kelas XI semester genap SMA Negeri 1 Binjai Kabupaten Langkat T.P. 2014/2015. (2) Untuk mengetahui pengaruh model pembelajaran Discovery learning terhadap hasil belajar siswa pada materi pokok Fluida Dinamis di kelas XI semester genap SMA Negeri 1 Binjai Kabupaten Langkat T.P. 2014/2015. (3) Untuk mengetahui aktivitas siswa dengan menggunakan model pembelajaran Discovery learning pada materi pokok Fluida Dinamis di kelas XI semester genap SMA Negeri 1 Binjai Kabupaten Langkat T.P. 2014/2015.

\section{METODE PENELITIAN}

Penelitian ini dilaksanakan di kelas XI SMA Negeri 1 Binjai Kabupaten Langkat yang berada di jalan Yos Sudarso, Desa Suka Makmur, Kabupaten Langkat, pada semester genap tahun ajaran 2014/2015.

Populasi dalam penelitian ini adalah seluruh siswa kelas XI SMA Negeri 1 Binjai Kabupaten Langkat yang terdaftar pada semester genap T.P. 2014/2015 dengan jumlah tiga kelas.

Sampel dalam penelitian ini terdiri dari dua kelas yaitu kelas eksperimen dan kelas kontrol yang diambil dengan teknik cluster random sampling. Kelas eksperimen yaitu kelas yang diajarkan dengan dengan menggunakan model pembelajaran discovery learning pada materi pokok Fluida Dinamis, sedangkan kelas yang lain sebagai kelas kontrol, yaitu kelas yang diajarkan dengan menggunakan model pembelajaran konvensional pada materi pokok Fluida Dinamis.

Desain penelitiannya pada penelitian ini berupa Pretest-postest Control Group Design sebagai berikut:
Tabel 1 Pretest-Postest Control Group Design

\begin{tabular}{|l|l|l|l|}
\hline Kelas & Pretest & Perlakuan & Postes \\
\hline Eksperimen & $\mathrm{T}_{1}$ & $\mathrm{X}$ & $\mathrm{T}_{2}$ \\
Kontrol & $\mathrm{T}_{1}$ & $\mathrm{Y}$ & $\mathrm{T}_{2}$ \\
\hline
\end{tabular}

Keterangan :

$\mathrm{T}_{1}=$ Pemberian tes awal (pre-tes)

$\mathrm{T}_{2}=$ Pemberian tes akhir (pos-tes)

$\mathrm{X}=$ Perlakuan dengan model pembelajaran berbasis masalah

$\mathrm{Y}=$ Perlakuan dengan model pembelajaran konvensional

(Arikunto,1997)

Analisis data menggunakan uji $t$, apabila data penelitian berdistribusi normal dan homogen maka untuk menguji hipotesis menggunakan uji $\mathrm{t}$ (Sudjana, 2005).

\section{HASIL PENELITIAN \\ PEMBAHASAN} DAN

Penelitian diawali dengan memberikan pretes terhadap kedua sampel dengan jumlah soal 20 butir dalam bentuk pilihan berganda dengan 5 option yaitu pada kelas eksperimen dan kelas kontrol.

Hasil pretes kelas eksperimen memperoleh nilai rata-rata 32,62 dan nilai rata-rata pretes kelas kontrol adalah 32,08 dan dapat di lihat pada gambar di bawah ini:

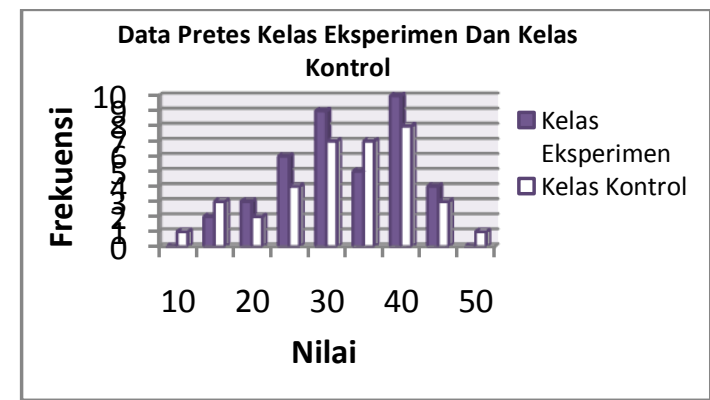

Gambar 1. Diagram pretes kelas eksperimen dan kontrol

Hasil pengujian menggunakan uji t menyatakan bahwa kemampuan awal siswa pada kelas eksperimen sama dengan kemampuan awal kelas kontrol sebelum diberi perlakuan. Hasil uji normalitas untuk kedua sampel diperoleh bahwa nilai pretes 
berdistribusi normal dimana dan berasal dari populasi yang homogen. Perlakuan yang berbeda diberikan untuk kedua kelas tersebut yaitu pada kelas eksperimen diberi perlakuan menggunakan model pembelajaran discovery learning sedangkan kelas kontrol diberi dengan menggunakan model pembelajaran Konvensional. Setelah diberikan perlakuan kedua kelas diberikan tes akhir (postes) untuk melihat adanya perbedaan akibat diberi perlakuan pembelajaran yang berbeda. Hal ini dapat dilihat dari hasil rata-rata postes kelas eksperimen, memperoleh nilai rata-rata 73,87dengan standar deviasi 9,96 dan variansnya 99,34. Sedangkan nilai rata-rata postes kelas kontrol, memperoleh nilai rata-rata 61,11 dengan standar deviasi 10,15 dan variansnya 103,01 dan dapat di lihat pada gambar dibawah ini:

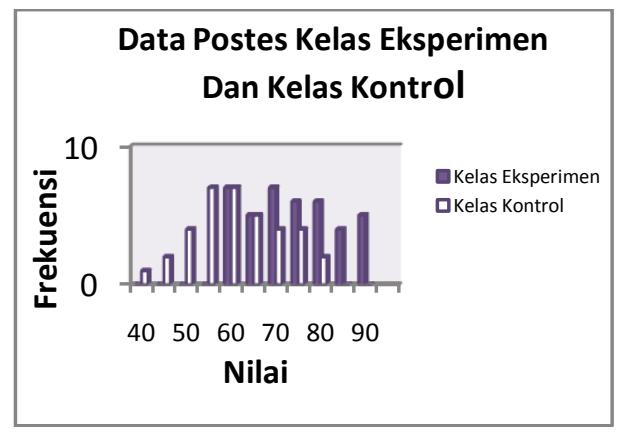

Gambar 2. Diagram postes kelas eksperimen dan kontrol

Hasil uji hipotesis untuk postes menggunakan uji $t$ pada taraf signifikan $\alpha=0,05$ diperoleh thitung $>$ $t_{\text {tabel }}(5,52>1,66)$ yang berarti bahwa ada pengaruh yang signifikan terhadap hasil belajar siswa yang menggunakan model pembelajaran discovery learning dengan model pembelajaran konvensional.

Peningkatan hasil belajar menggunakan model pembelajaran discovery learning lebih baik disebabkan model pembelajaran ini dikombinasikan dengan metode diskusi dan praktikum yang menarik bagi siswa yaitu melakukan praktikum dan diskusi dengan menggunakan animasi
PhET dengan tujuan untuk lebih meningkatkan pemahaman siswa. Pembelajaran ini tentu dapat menyajikan materi pelajaran yang lebih menarik, tidak monoton, dan memudahkan penyampaian serta pemahaman siswa terhadap materi yang dipelajari.

Nilai kemampuan memecahkan kelas eksperimen lebih tinggi daripada nilai kemampuan memecahkan masalah kelas kontrol. Hal ini menjukkan kemampuan memecahkan masalah siswa yang pembelajarannya menggunakan model discovery learning lebih baik daripada kemampuan memecahkan masalah siswa yang pembelajarannya menggunkan model pembelajaran konvensional.

Hasil analisis menunjukkan bahwa pembelajaran dengan menggunakan model discovery learning berpengaruh pada kemampuan memecahkan masalah fisika siswa. Model tersebut dapat meningkatkan kemampuan memecahkan masalah fisika siswa pada pokok bahasan fluida dinamis. Hal ini dikarenakan karakteristik dari model discovery learning yang menuntut siswa untuk melakukan sebuah penemuan terhadap suatu konsep, sehingga jika mereka menemukan dan mengalaminya sendiri akan jauh lebih lama mengingat dan lebih baik pemahamannya, karena pemahamannya yang lebih inilah membuat siswa memecahkan masalah fisika dengan lebih baik.

Penelitian ini juga didukung oleh Indarti, dkk., (2013) menyatakan metode discovery dapat meningkatkan pemahaman konsep siswa. Siswa mengkaitkan kesamaan konsep yang telah mereka pelajari guna menemukan konsep baru tentang materi yang sedang dipelajari guna menemukan konsep baru. Sejak awal siswa yang belajar dengan metode discovery telah terlatih menemukan konsep baru untuk menyelesaikan masalah.

Uraian beberapa pernyataan dapat disimpulkan bahwa model 
discovery learning dapat meningkatkan kemampuan memecahkan masalah. Hal ini tampak dari hasil penelitian, model discovery learning dapat meningkatkan kemampuan memecahkan masalah karena didalam model ini terdapat aktivitas siswa langsung, kegiatannya berpusat pada siswa sehingga siswa lebih faham pada konsep fisika yang sedang dipelajari, pada akhirnya mampu memecahkan masalah fisika dengan baik.

Nilai aktivitas pada kelas eksperimen sangat baik dan selalu mengalami peningkatan. Rata-rata aktivitas siswa sebesar 71,48, 79,1 dan 83,7.

Model pembelajaran discovery learning dapat memberikan dampak positif terhadap siswa, model pembelajaran ini mampu memberikan kesempatan bagi siswa untuk lebih aktif dalam proses pembelajaran, melalui perlakuan model pembelajaran discovery learning, siswa terlibat pada persoalannya, menemukan prinsipprinsip dan jawaban lewat percobaan. Siswa terlibat dalam kelompok untuk melakukan percobaan. Setiap kelompok beranggotakan lima siswa sehingga mereka bisa saling membantu dengan cara bekerjasama untuk menemukan konsep, prinsip, atau jawaban lewat praktikum padamateri Fluida Dinamis.

Pada fase pertama dalam memberikan stimulus atau rangsangan kepada siswa, peneliti memberikan stimulus melalui tayangan video. Pada fase kedua, peneliti memberikan masalah kepada siswa dengan menunjukkan suatu permasalahan, kemudian peneliti membagi siswa kedalam bentuk kelompok lalu membagikan LKS. Pada fase ketiga, peneliti memberikan waktu kepada siswa untuk mengumpulkan data melalui percobaan yang ada di LKS.

Pada fase keempat, peneliti memberikan waktu kepada siswa untuk mengolah data yang telah didapat melalui observasi ataupun percobaan (eksperimen). Pada fase kelima, peneliti memberikan kesempatan kepada siswa untuk menemukan suatu konsep, teori, aturan atau pemahaman melalui contoh - contoh yang jumpai dalam kehidupannya, lalu memverifikasi data yang terlah didapat dengan konsep yang sebenarnya. Peneliti meminta satu/dua kelompok untuk mempresentasikan hasil analisis LKS. Pada fase keenam, peneliti membimbing siswa menarik kesimpulan yang dapat dijadikan prinsip umum dan berlaku untuk semua kejadian atau masalah yang sama dengan memperhatikan hasil verifikasi.

Beberapa kelebihan dari model pembelajaran discovery learning adalah (1) Siswa dapat berpartisipasi aktif dalam pembelajaran yang disajikan, (2) Meningkatkan motivasi belajar siswa, (3) Mendukung kemampuan problem solving siswa, (4) Siswa mengerti konsep-konsep dasar dan ide-ide lebih baik, (5) Materi yang dipelajari dapat mencapai tingkat kemampuan yang tinggi dan lebih lama membekas karena siswa dilibatkan dalam proses menemukannya (Hosnan, 2014).

Perlakuan model pembelajaran discovery learning telah membuat hasil belajar yang lebih baik dan dapat meningkatkan aktivitas siswa, tetapi selama pembelajaran masih ada kendala yang dihadapi, yaitu siswa belum terbiasa melakukan percobaan dan diskusi, sehingga kegiatan tersebut masih kurang efektif. Selain itu siswa juga tidak terbiasa belajar kelompok. Pelaksanaan penelitian ini juga mengalami kendala dalam kegiatan belajar mengajar yaitu dominasi siswa tertentu didalam suatu kelompok pada proses praktikum dimana siswa yang lebih aktif adalah siswa yang memilik kemampuan lebih tinggi daripada siswa lain dalam kelompok tersebut sedangkan siswa dengan kemampuan lebih rendah terlihat pasif dalam berdiskusi. Selain itu banyak siswa dalam suatu kelompok juga mengakibatkan beberapa siswa menjadi 
pasif. Selain itu peneliti juga dalam melaksanakan semua sintaks saat pelaksanaan proses pembelajaran masih kurang efektif di karenakan belum maksimalnya dalam mengelola waktu. Oleh sebab itu, upaya yang dilakukan adalah dengan membuat pembelajaran menjadi lebih menarik dan peneliti juga lebih memperhatikan siswa selama bereksperimen, yaitu dengan penggunaan metode yang merangsang siswa menjadi lebih aktif dan penggunaan waktu harus diefektifkan semaksimal mungkin, supaya tiap-tiap tahap dalam model pembelajaran discovery learning berjalan dengan baik.

\section{KESIMPULAN DAN SARAN Kesimpulan}

Berdasarkan data hasil penelitian yang diperoleh dan analisa data serta pengujian hipotesis maka dapat disimpulkan sebagai berikut : (1) Nilai rata-rata hasil belajar siswa pada kelas eksperimen yang diberi perlakuan dengan model pembelajaran discovery learning adalah 73,87. Nilai rata-rata hasil belajar siswa pada kelas kontrol yang diberi perlakuan dengan pembelajaran konvensional adalah 61,11. (2) Terdapat pengaruh yang signifikan terhadap model pembelajaran discovery learning terhadap hasil belajar siswa pada materi pokok Fluida Dinamis di kelas XI Semester Genap SMA Negeri 1 Binjai Kabupaten Langkat T.P. 2014/2015. (3) Aktivitas belajar siswa selama mengikuti pembelajaran dengan menggunakan model pembelajaran discovery learning pada materi pokok Fluida Dinamis di kelas XI Semester Genap SMA Negeri 1 Binjai Kabupaten Langkat T.P. 2014/2015 adalah meningkat dari pertemuan pertama memiliki rata-rata aktivitas sebesar 71,48 menjadi 79,1 untuk rata-rata aktivitas pada pertemuan kedua dan menjadi 83,7 untuk rata-rata aktivitas pada pertemuan ketiga.

\section{Saran}

Berdasarkan hasil dan kesimpulan dalam penelitian ini, maka peneliti mempunyai beberapa saran,yaitu : (1) Bagi guru bidang studi fisika di SMA Negeri 1 Binjai Kabupaten Langkat agar berkenan mencoba menggunakan model pembelajaran discovery learningdalam melaksanakan kegiatan pembelajaran sebagai salah satu alternatif untuk meningkatkan aktivitas dan hasil belajar siswa. (2) Bagi para peneliti selanjutnya yang tertarik untuk meneliti dengan model pembelajaran discovery learning, agar mendapatkan hasil yang lebih baik, disarankan untuk memperhatikan pembagian kelompok. Pembagian kelompok sebaiknya jumlah siswa dalam setiap kelompok cukup 3-4 orang. (3) Bagi para peneliti selanjutnya yang ingin meneliti model yang sama disarankan melakukan penelitian pada lokasi dan materi pokok yang berbeda serta terlebih dahulu memperhatikan kelemahan-kelemahan dalam penelitian ini untuk memperoleh hasil belajar yang lebih baik.

\section{DAFTAR PUSTAKA}

Arikunto, S., (1997), Prosedur Penelitian, PT Rineka Cipta, Jakarta.

Hosnan, (2014), Pendekatan Saintifik Dan Kontekstual Dalam Pembelajaran Abad 21, Ghalia Indonesia, Bogor.

Indarti, Suyudi, dan Yogihati, (2013), Pengaruh Model Discovery learning Terhadap Kemampuan Memecahkan Masalah Siswa Kelas X SMAN 8 Malang, Universitas Negeri Malang, Malang.

Lestari, P., 2015, Laporan Studi Pendahuluan, Medan

Sudjana., (2005), Metode Statistika, Tarsito, Bandung.

Education For All Global Monitor (2011), http://news.okezone.com/read/ 2013/06/01/373/816065/astaga-riperingkat-ke-64-untukpendidikan (02 Desember 2014） 
Jurnal Inpafi

Volume 3 Nomor 4 Nopember 2015 